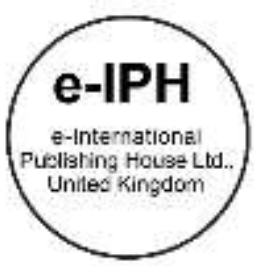

\title{
Conceptual Framework for the Intervention on Childhood Obesity Management for School Health Nurses and School Children in Malaysia
}

\author{
${ }^{1}$ Centre for Nursing Studies, ${ }^{2}$ Centre of Nutrition and Dietetics, \\ Faculty Health Sciences, \\ Universiti Teknologi MARA (UiTM), Malaysia \\ norimah2809@puncakalam.uitm.edu.my
}

Norimah Said ${ }^{1}$, Norazmir Md Nor², Siti Khuzaimah Ahmad Sharoni' ${ }^{1}$ Siti Sabariah Buhari Tel. +60102267514

\begin{abstract}
This article aims to present the conceptual framework for the Intervention Health Educational Module and C.H.A.N.G.E design on Childhood Obesity Management for School Health Nurses towards obese school children. Social Cognitive theory, Urie Bronfenbrenner, and Kolb's model of Learning Styles and Experiential Learning will be used in this study to modify and make changes on the knowledge, attitude, behavior, and environment among obese school children. This study aims to provide a new model on the development of the professional role of nurses in the School Health Program (SHP) and health education promotion towards obese school children to improve their quality of life.
\end{abstract}

Keywords: obesity; school children; school nurses; conceptual framework

eISSN: 2398-4287 @ 2019. The Authors. Published for AMER ABRA cE-Bs by e-International Publishing House, Ltd., UK. This is an open access article under the CC BYNC-ND license (http://creativecommons.org/licenses/by-nc-nd/4.0/). Peer-review under responsibility of AMER (Association of Malaysian Environment-Behaviour Researchers), ABRA (Association of Behavioural Researchers on Asians) and cE-Bs (Centre for Environment-Behaviour Studies), Faculty of Architecture, Planning \& Surveying, Universiti Teknologi MARA, Malaysia.

DOI: https://doi.org/10.21834/e-bpj.v4i10.1593

\subsection{Introduction}

Nurses play an important role in health care setting whether in Malaysia or other countries in the world. Mainly, the role of the nurse contributes to the health and welfare of society. The Code of Professional Conduct Malaysia has stated that nurses must play their role to provide care to individuals, families, and communities through the protection from and prevention of illnesses such as communicable and non-communicable diseases as well as the promotion of restoration of health for rehabilitation and recovery phase including the alleviation of suffering from chronic or acute pain related to the disease (Nursing Board Malaysia, 1998). Furthermore, the nursing services in the health care setting of Malaysia are in primary care and secondary care (hospital). In primary care, the nursing services include the School Health Program (SHP) (Sirajoon \& Hematram, 2008) that is managed by School Health Nurses (SHN). Thus, this paper seeks to highlight the theoretical conceptual framework for the intervention of structured health education on the Childhood Obesity Management (COM) integrated with the role of the SHN towards obese school children in Malaysia that will be implemented in the School Health Program (SHP). Therefore, the role of SHN in the SHP can be divided into five core nursing activities and care (Yadav, Chan \& Lan,2011). The first core entails preparing pre-visit plans to the school, assessing the health status and screening (height, weight, BMl and Blood Pressure). Thus, this has to be followed by a physical examination, taking note of the children's health history, performing observation, vision test, and hearing test, conducting health education for the problem that has been identified or addressing common issues related to the school children, and, lastly, providing minor and emergency treatments and health care referral and care coordination. 


\subsection{Problems statement}

The Guidelines for School health services in Malaysia (Kementerian Kesihatan Malaysia, 2013) states that the SHN nurses are required to advise on the nutrition for school children who are identified as obese or overweight. The SHN anticipated the monitoring of nutritional problems related to obesity within six months. If the problems continue to arise for the six months, the $\mathrm{SHN}$ is required to refer the case and advise the parents or teacher to obtain treatment at a health clinic. Also, SHN need to refer the school children to a nutritionist for further management. Based on this guideline, it shows that $\mathrm{SHN}$ is required to monitor the condition of the school children for six months. Moreover, to ensure that obesity prevention or intervention could be transferred successfully by SHN, they must use innovative approaches and, based on the theory, the intervention component and stakeholder involvement must be adequately measured (Tucker \& Lanningham-Foster, 2015).

Besides that, the role of the $\mathrm{SHN}$ in prevention and intervention is not fully developed as studies about this are scarce, and there is a limited amount of school health programs in Malaysia. Furthermore, there is a lack of empirical studies of school-based intervention and there is insufficient evidence conducted by the SHN. Meanwhile, studies have also demonstrated that there are some barriers and inconsistencies when trying to educate, communicate, and provide services related to the prevention of obesity and towards practicing a healthy lifestyle for the children and families. The research seeks to illuminate and leverage specific roles for school nurses when it comes to obesity prevention and intervention. A systematic review suggests that $\mathrm{SHN}$ can play a key role in implementing sustainable and effective school-based obesity interventions (Krista, Travers, \& Smaldone, 2016). In addition, the obesity prevention program is obligatory to be continued because several school-based interventions may be dismissed when the intervention has been completed (Schey, Luther, \& Rose, 2016). The school-based interventions that involve nurses are effective and may be better suited to obesity prevention in the healthy habits' education or counseling and could be more appropriate for all children with different body weights (Schey et al., 2016).

Specifically, health problems appear to be the result of obesity. It has been a public health problem which requires preventive measures and further treatment (Sharifah, 2011). In Malaysia, the prevalence of overweight and obesity continues to grow, and it has escalated to affecting children below 18 years old. The National Health and Morbidity Survey Report in 2015 (Ministry of Health, 2015) stated that the prevalence of obesity among children aged seven years old decreased from $14 \%$ to $8.3 \%$. However, the prevalence of overweight and obesity for children of 10 to 17 years old increased to $25 \%$ in the year 2015 as compared to $11.2 \%$ in the year 2011 and it was slightly higher among children in the urban areas which was $12.1 \%$ than in the rural regions, $11.2 \%$, and significant among boys which was about $13.6 \%$ as compared to girls, which was only $10.0 \%$. Thus, the obesity problem among school children aged 7 to 12 years old needs proactive prevention and management because it can lead to poor quality of life.

\subsection{The Objectives}

This study aims to develop and evaluate the Health Education Module (HEM) on Childhood Obesity Management (COM) for SHN towards obese school children in Malaysia. Furthermore, the specific objective is to determine the attitudes, barrier, skills, and training required by SHN on COM followed by the development of the HEM on COM that will be used by SHN in Malaysia. Lastly, the study is also interested in evaluating the effects of HEM on COM for knowledge, practice behavior, attitude, self-regulation, and Body Mass Index (BMI).

\subsection{Literature Review}

The alarming rate of childhood obesity requires the preventive measure against this problem from becoming a reality either locally or internationally. Some of the questions highlight, "How can the nurses play a role in the prevention of obesity?". SHN can assess the socioeconomic status such as education status, housing, and career to the child and family, and then make recommendations to the families on how they can change their current lifestyle habits. Similarly, the report by CDC (Centers For Disease Control And Prevention, 2014) and the World Health Organization (2014) informed that children from low socioeconomic status, negative attitude, and poor practice by parents followed by an unhealthy environment are the contributing factors to the prevalence of obesity among school children (Nordin, Said, Nordin, \& Adnan, 2018). Nurses can play a significant role in educating school children about general health, healthy eating, and physical activity. Thus, in Malaysia, this role was stated in Garis Panduan Perkhidmatan Sekolah (Kementerian Kesihatan Malaysia, 2013) The SHN needs to be creative in the delivery of obesity education, and the message will be delivered effectively and efficiently. For this reason, the SHN needs to ensure that the interest level of the school children is assessed before the education is implemented. Thus, without the interest and motivation to listen and be engaged in health teaching, health education will not meet the outcome as planned (Pelletier, 2015).

A previous study shows that the nurses play an important role in the childhood obesity prevention including the education and management in the school setting by undertaking some assessment and education (Nauta, Byrne, \& Wesley, 2009). This is also supported by the U.S Department of Health and Human Services (USDHHS, 2014) in which the nurses play a significant role to improve the nutrition and weight status of school children through screening, nutrition education, and referring. Furthermore, currently, nurses are involved as part of the multidisciplinary team through the collaboration with parents, students, school food personnel, pediatricians and other health care members who are interested in the issue of childhood obesity (Maughan et al., 2016). The current role and practices of the nurses in the management of obesity among school children entail the provision of counseling, education, and body measurement (Melin \& Lenner, 2009). After that, the nurses are involved in individual counseling and information is provided using pamphlets on weight management using motivational interviewing and parental counseling via the telephone (Pbert, 2012; Wong \& Cheng, 2013). In the year 2013, the nurses also performed their role to assist with the intervention design, parent education, and to 
provide support groups including the weekly classroom education sessions (Wright et al., 2013; Tucker \& Lanningham-Foster, 2015).

\subsection{Methods and Analysis}

\subsection{Study design}

This study will employ an experimental design with two groups: intervention and control. A school categorized as the intervention group will receive the HEM to evaluate the effect of the module in the pre and post-tests. Meanwhile, a school in the control group will evaluate both the pre and post-tests without the implementation of the module.

\subsection{Study setting}

The study setting will be a primary school located in the state of Selangor. Selangor has been chosen as the study setting because it has a higher number of the population totaling 188,501 primary school children as compared to other states (National Health and Morbidity Survey, 2015).

\subsection{The characteristic of participants}

The population for this study is school children from primary school under the Jabatan Pendidikan Negeri Selangor. The school children who will be enrolled in the study are from level one to the level two , aged 7 to 12 -years-old.

\subsection{Determination of sample size}

The sample consists of primary school children and parents. The pilot study is used to evaluate the effect of HEM, the minimum sample size required for the testing calculated is 60 participants (Thivel et al., 2011) or 30 participants per group after considering a 20\% dropout rate.

\subsection{Sampling method procedure}

A multistage probability sampling will be applied in this study with an independent person or one who is not involved in this study to choose the location of the school. He or she will be asked to carry out the randomization procedure. After that, the primary school children that will be involved in this study will be selected through purposive sampling when they are identified as obese school children, who happen to agree to participate in this study.

\subsection{Material and Procedure}

\section{1 Conceptual Framework Intervention HEM}

A conceptual framework based on theory was developed for this HEM. The theoretical background for the development of the Conceptual Framework Intervention in the HEM is based on the Social Cognitive Theory (SCT) by Bandura (2001) and Urie Bronfenbrenner model by Bronfenbrenner (1994). The concept of the Urie Bronfenbrenner model is to ensure the normal growth and development of the children in general without any goals related to health. However, in this study, the Urie Bronfenbrenner model will be used as an emphasis on action and making changes in the knowledge, attitude, expectations, and behavioral modification. Meanwhile, Kolb's model of Learning Styles and Experiential Learning (Kolb,1984) suggests that each session of learning activities must address each of the learning styles following this sequence: concrete experience, observations, and reflections, understanding the concepts and generalizations and testing the implications of concepts in new situations for the environmental influences. Moreover, the SCT will explain how the individual engages between environment and sociocultural factors to produce behavioral effects. In this theory, it is stressed that personal behavior includes self-regulation in the learning process. Furthermore, in this study, the Urie Bronfenbrenner model focuses on the microsystem which refers to the development of HEM with a primary focus on the education and environment around the school that will influence obese school children related to their daily learning through the role of the SHN and health education that will be introduced (Bronfenbrenner, 1994). Meanwhile, mesosystem refers to the relationship between the individual and environment such as the environment of the school, family, and nurses. Jalloh (2007) noted that school-based health education provides an opportunity to discover the best way to influence positive-health-related change for the youth to achieve their health goals. Besides that, the effective involvement of SHN in the school's health education has been proven to help parents and children to avoid obesity complication by way of addressing the problem through the monitoring of weight control, healthy eating, and consistent physical activity (Pelletier, 2015). The rationale for the development of the Conceptual Framework Intervention of HEM is to improve the knowledge, practice behavior, attitude, and self-regulation among obese school children on nutrition, physical activity, and healthy lifestyle in COM. Furthermore, it can improve the health outcome and reduce the risk of obesity problems. Previous literature shows that developing a positive attitude towards healthy eating needs to be incorporated early during childhood to influence dietary practices until adulthood (Macharia-Mutie, Kigaru, Moleah, Ndungu, \& Loechl, 2015).

Based on that, Figure 1 explains how the integration between that theory and the role of SHN together with the involvement of parents to change the attitude and practice behavior, will improve the knowledge among obese school children. In general, in order for an obese school child to practice good behavior and attitude for health reasons (in preventing complication obesity), their knowledge must be improved first. After that, obese school children will have the awareness to practice good behavior and change their attitude 
related to nutrition, physical activity, and a sedentary lifestyle (evaluation). He or she must believe that consuming healthy food alongside practicing healthy behavior and attitudes will improve their self-regulation on the prevention complications with regards to obesity problems (outcome). After that, the obese school children will self-regulate their practice and attitude and make a change in their body mass index (BMI).

Furthermore, in this Conceptual framework, it is also explained that delivering methods for the educational module will be appropriate to the school children when they address the school children's cognitive, emotional, and social development by using Kolb's model of Learning Styles and Experiential Learning. This model suggests individual differences where they understand their experiences of and adapt to the world and their variances can be placed on a continuum of perception (Kolb, 1984).

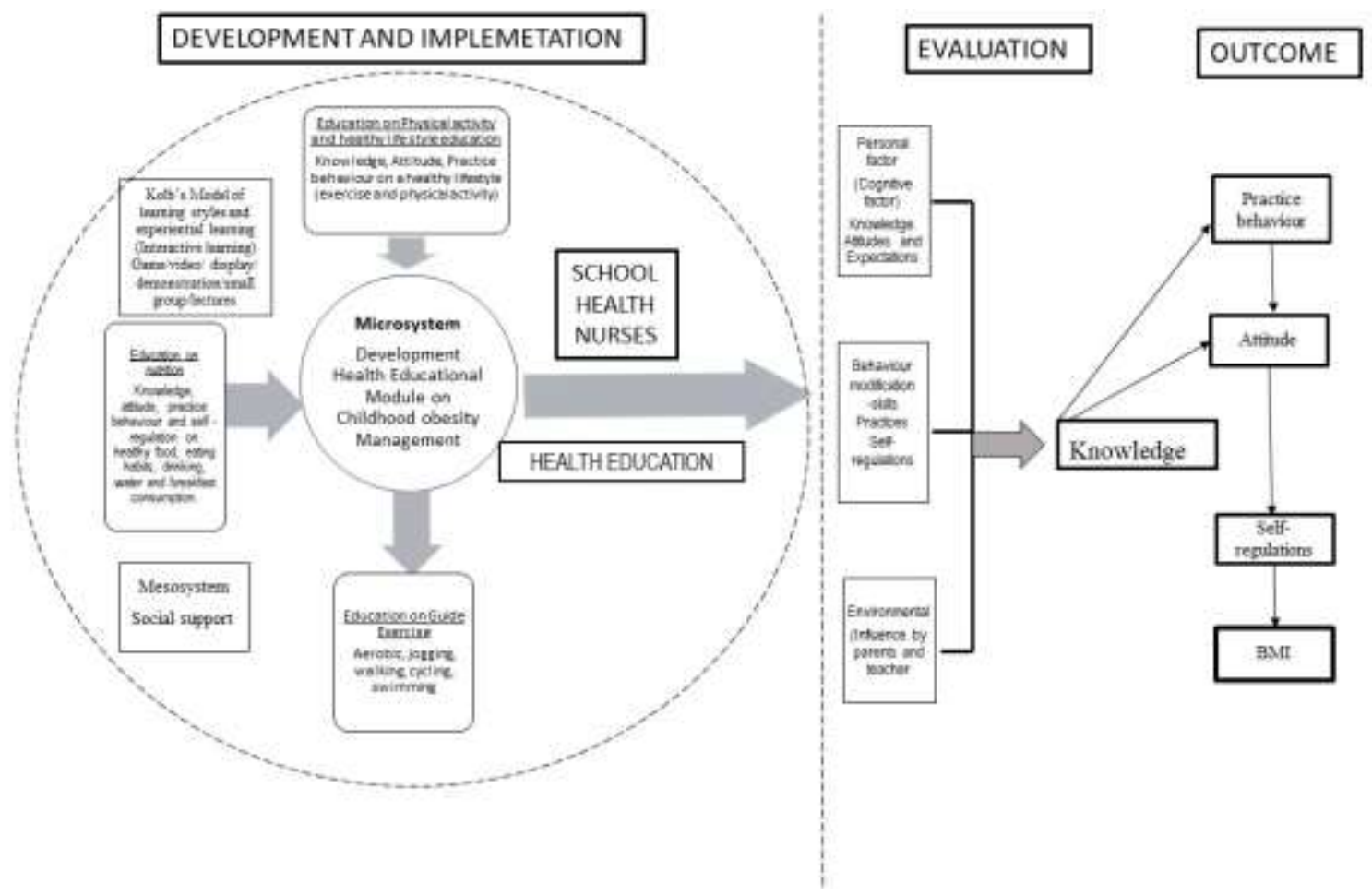

Figure 1: A conceptual framework of the development and evaluation of HEM for SHN on nutrition, physical activity, exercise and healthy lifestyle towards obesity among primary school children in Malaysia

The comprehensive HEM will be developed based on the various topics related to healthy lifestyle, nutrition, physical activity, and obesity prevention that follow several guidelines from the Centers for Disease Control and Prevention (2018), Malaysian Dietary Guideline (MDG) for Children and Adolescent (2015), World Health Organization (2014), and Nutri Web (2014). The design for HEM is "C.H.A.N.G.E" where the $\mathrm{C}$ refers to choose, $\mathrm{H}$ refers to the health, $\mathrm{A}$ refers to an activity, $\mathrm{N}$ refers to nutrition, $\mathrm{G}$ refers to guide, and $\mathrm{E}$ refers to exercise. In other words, the meaning is "Choose Healthy Activity, Nutrition, Guide, Exercise" The educational module will provide the intervention with various instructional designs of health education for primary school children to enhance their knowledge, attitude, practice behavior, and self-regulation among obese school children. Thus, the development of HEM will provide the sustainable environment for obese school children in the delivery of the intervention, teaching health practices with a concentration on the health promotion and management of obesity to improve their quality of life (Souza et al., 2015).

\subsection{Development of Questionnaire}

The questionnaire in this study will be used to measure the research outcome for pre and post-tests for each of the educational modules. The primary school children need to answer the questionnaire before and after the implementation of the educational module. The study instrument questionnaire in this study will be adopted from a previous study. The questionnaire will consist of personal details such as sex, residential zone, and the frequency of breakfast consumed using a self- administered questionnaire. All the primary school children will be screened for body composition such as weight, height, and BMI.

\subsubsection{Questionnaire for the outcome measures}

Part of a study instrument will be developed, and it will be adopted from the previous study. The outcome measure for the knowledge, practice behavior, and attitude on nutrition and practiced style and eating habits will be adapted from Dali, Mohamed, and Yusoff, (2017). The permission was obtained from the author to use the questionnaire in this study. In addition, this questionnaire has been translated into the Malay language and validated by the Malaysian population. The attitude on nutrition, healthy lifestyle, eating habits and physical activity will be using the Child Eating Behavior Questionnaire (CEBQ) (Wardle, Guthrie, Sanderson, \& Rapoport, 2001), and Physical 
Activity Questionnaire for Older Children (PAQ-C) (Kowalski, Ph, Crocker, \& Donen, 2004). Furthermore, the self-regulation towards the practices and attitude on a healthy lifestyle will be adopted from Self Regulations of Eating Behavior (SREB) (Kliemann, Beeken, Wardle, \& Johnson, 2016). Meanwhile, the outcome to evaluate the effect of the module is derived from the anthropometry measurement such as weight, height, and BMI. All the questions have been validated and reliable testing on the Malaysian population except the SREB questionnaire needs to be piloted on the Malaysian population as shown in Table 1.

\subsection{Pilot Study}

A pilot study of the questionnaire will be implemented to examine the reliability and to determine the homogenous population together with the pilot study of the Intervention Structured HEM after obtaining consequences from the experts. The aims of the implementation and evaluation of the pilot study are to develop and test the adequacy of the HEM and the questionnaire before it can be used for the study or the actual implementation as shown in Figure 2. This implementation of the pilot study will help the researcher to develop a final draft of the material and questionnaire carefully based on the comments given by the content experts and feedback from the primary school children. It will be recorded to help modify the design and content as well as the educational module before the actual implementation. Besides that, the researcher will provide Continuous Nursing Education (CNE) to the SHN before the actual health education in the educational module is emphasized. This will help the SHN to deliver health education in the HEM effectively.

Table 1: Construct development of the questionnaire

\begin{tabular}{|l|l|}
\hline \multicolumn{1}{|c|}{ Construct } & \multicolumn{1}{c|}{ Indicator/ variable } \\
\hline Socio-demographic & $\begin{array}{l}\text { Age, sex, residential zone, race, parent information such } \\
\text { as education, job, income, and status - economy. }\end{array}$ \\
\hline Knowledge & $\begin{array}{l}\text { The level of knowledge of nutrition, physical activity, } \\
\text { exercise, and sedentary lifestyles. }\end{array}$ \\
\hline Practice behaviour & $\begin{array}{l}\text { The understanding and awareness to consume healthy } \\
\text { nutrition, physical activity, practice a healthy lifestyle and } \\
\text { eating habits. }\end{array}$ \\
\hline Attitude & $\begin{array}{l}\text { The understanding and awareness of the attitude towards } \\
\text { nutrition, healthy lifestyle, eating habits and physical } \\
\text { activity. }\end{array}$ \\
\hline Self-regulation & $\begin{array}{l}\text { The self - regulations towards practices and attitude on } \\
\text { healthy nutrition, practices, and attitude. }\end{array}$ \\
\hline Nutrition status & Anthropometry measurement (weight, height, BMI) \\
\hline
\end{tabular}

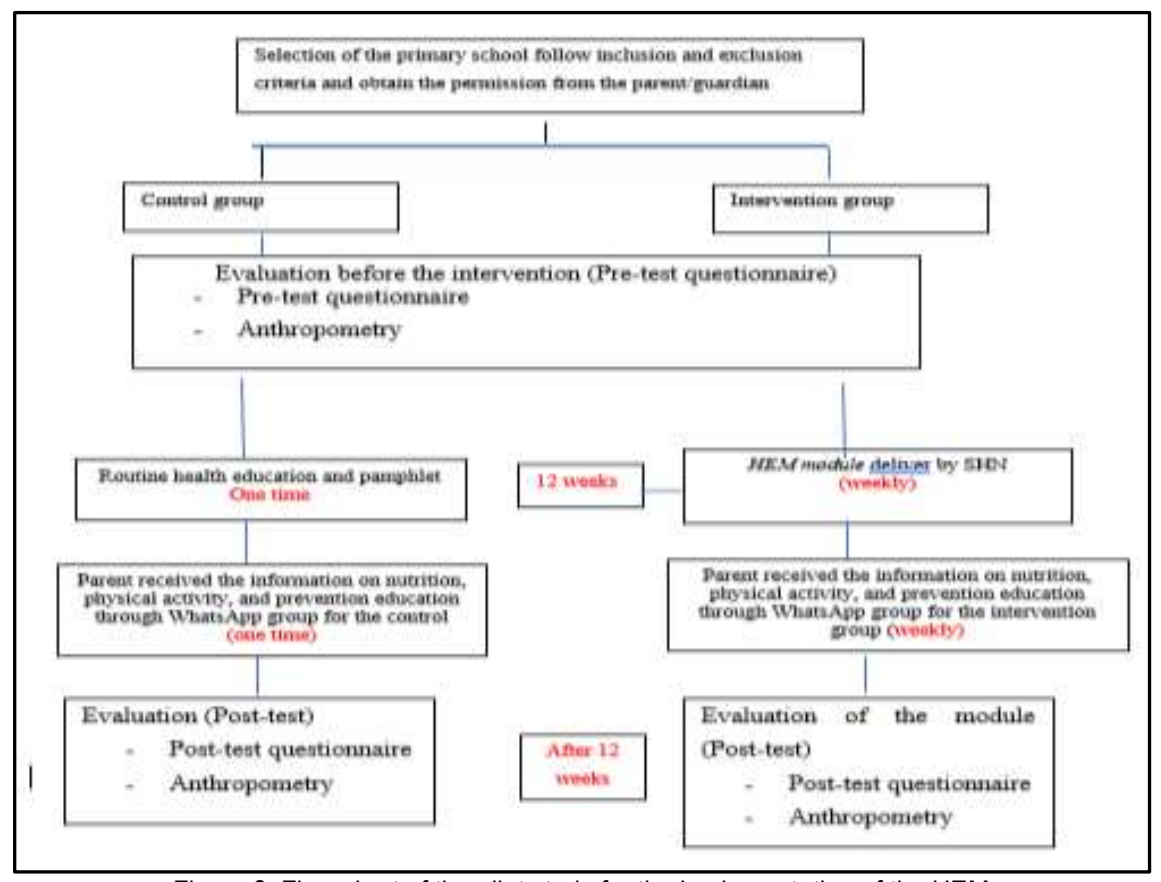

Figure 2: Flow chart of the pilot study for the implementation of the HEM

\subsection{The Future Outcome of the Study}

Malaysia has implemented Program Bersepadu Sekolah Sihat (PBSS) or Integrated School Health Program (ISHP) (Ahmad Husairi, 
2014 ) to provide a healthy school environment. However, $28.2 \%$ of the students never heard about the programme. It shows the importance of clarity to the students about the program running at the school to ensure that there are active participants (Hoque et al., 2016). Thus, the result of this study shows that SHN plays an important role in supporting the prevention of obesity at school and drawing the line between the role of SHN and nutritionists. Thus, the nutritionist can focus on treating obese school children. Meanwhile, the SHN in Malaysia also need to provide education or advice to overweight and obese school children , and how they can provide education on prevention is still questionable. Thus, considering this differences in other countries such as the United States and the United Kingdom, the SHN play an important role in preventing and treating the issues of overweight and obesity. Since this study integrates the role of nurses, it is required to identify the current practice of SHN in delivering health education or advice on nutrition to the school children. The information from the findings of this study may contribute to the managerial data especially to develop the professional role of the nurses in the School Health program at school. Furthermore, it will provide baseline information for the Malaysian Ministry of Health and Ministry of Education to ensure the future of health education and promotion that integrates the role of nurses with the aim to help increase the health awareness among primary school children and parents towards the prevention of obesity.

\subsection{Ethical Consideration}

The ethical approval will be obtained from the UiTM Research Ethics Committee, National Medical Research Register, and the Ministry of the Education and Jabatan Pendidikan Negeri Selangor. The parents and respondents will be informed about the study topic before they are asked to give their consent. In order to assist the parents and respondents in understanding the reasons for the study, the information sheet and consent form will be written in two languages; Malay and English.

\subsection{Conclusion}

The issue of obesity is not a new epidemic but it is a worldwide and global problem. The factor that contributes to the obesity problems is dietary intake, sedentary lifestyle, lack of knowledge, practice behavior and attitude towards healthy nutrition, and physical activity. Furthermore, prevention is better than cure and this is one of the approaches that can be applied to prevent obesity among school children. The SHN will able to play an important role in the prevention of obesity because they are a front liner in the health care system in Malaysia. The lack of empirical studies that integrate the role of the nurses in the intervention programme for the obese school children is the gap in this study. Besides that, limited studies on creating the awareness programme for the overweight and obese school children that is handled by nurses in Malaysia. It is hoped that, later on, this study will contribute to the future development of the professional role of nurses in schools and to improve the quality of life as well as provide environmental support to the school children.

\section{References}

Ahmad Husairi K. 2014. Program Bersepadu Sekolah Sihat. Available at https://prezi.com/ qvs0ue4jes3y/program-bersepadu-sekolah-sihat-pbss/ (accessed 10 July 2018)

Bandura, A.( 2001). Social Cognitive Theory: An Agentic Perspective. Ann Rev of Psych. 52:1-26. doi: 10.1146/annurev.psych.52.1.1

Bronfenbrenner, U. (1994). Ecological models of human development. Readings on the Development of Children. https://doi.org/http://www.psy.cmu.edu/ siegler/35bronfebrenner94.pdf

Centers for Disease Control and Prevention. State Indicator Report on Physical Activity, 2014. Atlanta, GA: U.S. Department of Health and Human Services; 2014

Centers for Disease Control and Prevention, (2018, October 26). Nutrition, Physical Activity and Obesity. Retrieved from https://www.cdc.gov/nutrition/index.html

The Nutrition Society of Malaysia. (2014). Nutriweb. Retrieved from http://www.nutriweb.org.my

Centers For Disease Control And Prevention. (2014). 2014 State Indicator Report on Physical Activity. Centers For Disease Control And Prevention (CDC). https://doi.org/10.3945/an.114.007211

Dali, W. P. E. W., Mohamed, H. J. J., \& Yusoff, H. (2017). Nutrition knowledge, attitude and practices (NKAP) and health-related quality of life (HRQOL) status among overweight and obese children: An analysis of baseline data from the interactive multimedia-based nutrition education package(IMNEP) study. Malaysian Journal of Nutrition, 23(1), 17-29.

Hoque, K. E., Kamaluddin, M. A., Abdul Razak, A. Z., \& Abdul Wahid, A. A. (2016). Building healthy eating habits in childhood: a study of the attitudes, knowledge and dietary habits of schoolchildren in Malaysia. PeerJ, 4, e2651. https://doi.org/10.7717/peerj.2651

Jalloh,M.G.(2007).Health education careers in schools. The Health Education Monography,24(1),18-22

Kementerian Kesihatan Malaysia. (2013). Panduan, Garis Dan, Pemeriksaan Kesihatan, Pengendalian Untuk, Murid Pasukan, Anggota Sekolah, Kesihatan. (Unit Kesihatan Sekolah, Ed.), Kementerian Kesihatan Malaysia (1st ed., Vol. 1). Cawangan Kesihatan Keluarga, Bahagian Pembangunan Kesihatan keluarga, Jabatan Kesihatan Awam, Kementerian Kesihatan Malaysia. 
Kliemann, N., Beeken, R. J., Wardle, J., \& Johnson, F. (2016). Development and validation of the Self-Regulation of Eating Behaviour Questionnaire for adults. International Journal of Behavioral Nutrition and Physical Activity. https://doi.org/10.1186/s12966-016-0414-6

Kowalski, K. C., Ph, D., Crocker, P. R. E., \& Donen, R. M. (2004). The Physical Activity Questionnaire for Older Children ( PAQ-C ) and Adolescents ( PAQ-A ) Manual. Recreation. https://doi.org/10.1016/j.biotechadv.2011.08.021.Secreted

Krista, Travers, J., \& Smaldone, A. (2016). Are School Nurses an Overlooked Resource in Reducing Childhood Obesity? A Systematic Review and Meta-Analysis. The Journal of School Health, 86(5), 309-321. https://doi.org/10.1111/josh.12386

Maughan, Erin \& Bobo, Nichole \& Butler, Sarah \& Schantz, Shirley. (2016). Framework for 21st Century School Nursing Practice: National Association of School Nurses. NASN School Nurse. 31. 45-53. 10.1177/1942602X15618644.

Ministry of Health Malaysia. (2015). Malaysian Dietary Guidelines. Retrieved from http://www.nutriweb.org.my/downloads.pdf

Melin, A., \& Lenner, R. A. (2009). Prevention of further weight gain in overweight school children, a pilot study. Scandinavian Journal of Caring Sciences. https://doi.org/10.1111/j.1471-6712.2008.00651.x

National Health and Morbidity Survey 2015 (NHMS, 2015). (2015). National Health and Morbidity Survey 2015 (NHMS 2015). Vol. II: Non-Communicable Diseases, Risk Factors \& Other Health Problems. Ministry of health (Vol. II). https://doi.org/10.1017/CBO9781107415324.004

Nordin, R., Said, N., Nordin, F. F., \& Adnan, N. F. (2018). Influence of Parental Feeding Attitude, Style and Environmental Factors on BMl among School Children. Environment-Behaviour Procedings Journal, 3(7)(6th AicQoL2018Perhentianlsland), 19-24.

Noor Ghani, Sirajoon \& Yadav, Hematram. (2008). Health Care in Malaysia. University Malaya Press. ISBN 978-983-100-444-9

Nursing Board Malaysia. (1998). Code of Professional Conduct for Nurses. (Nursing Board Malaysia, Ed.), Nursing, Board Malaysia (First Edit, Vol. 99). Malaysia. Retrieved from http://nursing.moh.gov.my/wpcontent/uploads/2015/04/nursing_board_malaysia-code_of_professional_conduct_1998.pdf

Pbert L, Druker S, Gapinski MA, et al. A school nurse-delivered intervention for overweight and obese adolescents. J Sch Health. 2013;83(3):182-193.

Pelletier, M. (2015). The School Nurse Teacher's Role in Preventing Childhood Obesity at School.

Sharifah, W. W., Nur, H. H., Ruzita, a T., Roslee, R., \& Reilly, J. J. (2011). The Malaysian Childhood Obesity Treatment Trial (MASCOT). Malaysian Journal of Nutrition, $17,229-236$.

Schey, K. L., Luther, J. M., \& Rose, K. L. (2016). Are School Nurses an Overlooked Resource in Reducing Childhood Obesity? A Systematic Review and Meta-Analysis., 86(5), 1-21. https://doi.org/10.1021/acschemneuro.5b00094.Serotonin

Souza, K. M. M. de, Carvalho, P. M. S., Freitas, T. Á. S. De, Matins, R. A., Timbó, T. S., Cavalcante, T. G., ... Junior, W. F. A. (2015). Promoting Healthy Living in Childhood: An Action Research. Procedia - Social and Behavioral Sciences, 174, 1695-1699. https://doi.org/10.1016/j.sbspro.2015.01.823

Thivel D, Isacco L, Lazaar N, Aucouturier J, Ratel S, Dore E, Meyer M \& Duche P (2011). Effect of a 6-month school-based physical activity program on body composition and physical fitness in lean and obese schoolchildren. Eur J Pediatr 170 (11): 1435- 43

Tucker, S., \& Lanningham-Foster, L. M. (2015). Nurse-Led School-Based Child Obesity Prevention. The Journal of School Nursing, 31(6), 450-466. https://doi.org/10.1177/1059840515574002

U.S. Department of Health and Human Services (USDHHS). (2014). Healthy people 2020.Washington, DC: USA. Retrieved from: https://www.healthypeople.gov /2020/topics- objectives/topic/nutrition-and-weight-status/objectivesWater,

Wardle, J., Guthrie, C., Sanderson, S., \& Rapoport, L. (2001). Child Eating Behaviour Questionnaire. Journal of Child Psychology and Psychiatry.

Yadav, Hematram \& Chong, Mei \& Teik Lan, See. (2019). Community Health Nursing. Second Edition. 